\title{
Explaining Conflict in Low-Income Countries: Incomplete Contracting in the Shadow of the Future
}

\author{
By \\ Michael McBride \\ and \\ Stergios Skaperdas \\ Department of Economics \\ University of California, Irvine \\ Irvine, CA, 92697-5100, USA
}

March 28, 2005

revised: October 18, 2005

\begin{abstract}
We examine two factors that help explain the prevalence of conflict in low-income countries: that adversaries cannot enforce long-term contracts in arms, and that open conflict alters the future strategic positions of the adversaries differently than does peace. Using an infinite horizon model, we show the conditions under which adversaries will not be able to sustain short-term contracts even though doing so is Pareto superior to open conflict. Conflict arises because adversaries attempt to gain future strategic supremacy that only victory in conflict brings. Lower incomes or wages, as well as higher discount factors and the less destructive conflict is, the higher is the likelihood of war.
\end{abstract}

\section{Introduction}

During the post-WW II period civil wars have taken place in at least 73 countries with millions of casualties and economic costs that have greatly contributed to their slow, or negative, growth. ${ }^{1}$ From a traditional economic perspective it is difficult to understand such a record of apparent inefficiency. For setting aside

\footnotetext{
${ }^{1}$ An overview of the costs and other problems associated with conflict can be found in the World Bank report of Collier et. al. (2003). The number of countries mentioned is quoted from Fearon and Laitin (2003). Hess (2003) provides estimates of the indirect costs of conflict in terms of reduced trading and welfare that are about $8 \%$ of GDP on average for low-income countries, but of course are much higher for some countries and non-existent for other. For an overview of the recent academic literature on civil wars, see Sambanis (2004).
} 
the cost of arming, the question is why don't the different parties just settle their differences peacefully under the threat of conflict? Given that war is destructive, breaks the various complementarities in production and trade, and has a number of other external and indirect effects both in space and time (see Collier et. al., 2003), a peaceful settlement in the shadow of conflict would appear perfectly feasible. Such a peace would by no means necessitate disarmament. The Cold War or a traditional balance of power that periodically takes place for decades at a time could conceivably take place within countries between contending ethnic, class, or religious groups. Of course, such settlements do occur but our question, posed from an economic perspective, is why don't they always take place?

One possible explanation involves various forms of asymmetric information. The contending parties within a country might not know one another's strengths and weaknesses, preferences, capabilities, or any other attributes of the environment within which they are operating. It has been known for some time in economics that asymmetric information in any one dimension can by itself prevent the parties from attaining mutually beneficial trades. Models specifically addressing the possibility of conflict in the presence of mutually beneficial settlement when there is asymmetric information include Brito and Intriligator (1985) and Bester and Warneryd (1998). Especially when secrecy is important, as it is true in the case of coups for example, asymmetric information appears central to understanding why peaceful settlements might not occur (although asymmetric information is not necessary for coups, see McBride $\left.(2004)^{2}\right)$. However, many civil wars and low-level conflicts last for many years, even decades. The contending parties involved in such conflicts must have learned after a

\footnotetext{
${ }^{2}$ McBride (2004) describes how coups can arise due to incomplete contracting. When incumbent politicians cannot commit to efficient policies, they will resort to clientelist practices to gain popular support. If the incumbents are successful, political opponents' only way to gain political power is by attempting a coup.
} 
reasonable time period the principal aspects of one another's capabilities and preferences and, therefore, continuing conflict would be difficult to explain by means of asymmetric information. That is, the inability of the FARC and the various Colombian governments over the years or of the government of Angola and UNITA over that country's long civil war not to settle could hardly be considered an outcome of informational asymmetries.

In this paper we argue for a possible explanation of conflict that we think is empirically important but which has received much less attention than it deserves. There are two components in the explanation we discuss:

(i) Adversaries are unable to enforce long-term contracts on arming, although short-term contracts, conditional on arming and under the threat of conflict, can be written.

(ii) Open conflict changes the future strategic positions of the adversaries in different ways than does a peaceful contract under the threat of conflict.

The first component has become familiar to economists over the past two decades, especially for dynamic settings. ${ }^{3}$ If there are difficulties in writing or enforcing long-term contracts on items like the job-specific training an employee in a high-income country with a modern government and functioning institutions, it should not be surprising that enforcing long-term disarmament in a country with weak governance and institutions would be difficult. For arming is not just any item like job-specific training; in the presence of weak institutions it is the ultimate source that contending parties have at their disposal for enforcing other contracts. If contracts on arms cannot be written or enforced, arming can be expected to take place. Warfare, however, can be avoided since short-term contracts on everything else can be enforced given the arms possessed by each party. That is, condition (i) by itself is not sufficient to generate open conflict.

\footnotetext{
${ }^{3}$ Grossman and Hart (1986) introduced the main idea for the theory of the firm, whereby parties cannot write long-term contracts on relationship-specific investments. Skaperdas (2003) discusses how incomplete contracting relates to civil wars.
} 
What is also needed is a time dependence that is described in condition (ii). Open conflict results in winners and losers not just in terms of today's rewards but also by changing the strategic positions of the adversaries well into the future; typically, the winners have a higher chance of success and losers a lower one if they were to encounter each other in further future confrontations. A peaceful short-term contract, by contrast, does not dramatically change the future relative positions of the adversaries as open conflict does. There might be secular trends that favor one party over another but such a trend would be different from the change in strategic positions that comes about through open conflict. As long as open conflict and short-term settlements have different implications for the parties' future strategic positions, one or more parties might decide to forgo the short-term advantages of peace for the uncertain but higher expected future benefits that can come from open conflict.

A discussion of the ideas that we explore in this paper was in Fearon (1995). Skaperdas and Syropoulos (1996) showed how making the "shadow of the future" longer increases arming but did not distinguish between open conflict and settlement under the threat of conflict. Garfinkel and Skaperdas (2000) developed a finite-horizon model that actually demonstrates how open conflict occurs. Related in spirit is Acemoglu and Robinson's (2000) finding that there might not exist short-term transfers that could prevent a revolt. Powell (2004) also discusses the main issues and presents an illustrative model. Bester and Konrad (2004, 2005) examine the decisions of rivals on whether to attack or not to capture terrirory over finite or infinite horizons and show how large asymmetries in power or expectations of future equality can induce warfare. Mehlum and Moene (2005), although they do not distinguish between open conflict and settlement under the threat of conflict, concentrate on the role of the incumbency advantage that control of the state confers and how it stimulates arming.

In this paper we examine an infinite horizon model that shows how open 
conflict occurs within the context of low-income countries. Open conflict leads to destruction and therefore there is a short-run incentive to settle and peacefully divide the disputed output. War, though, eliminates one of the adversaries or increases the chance on winning a future war for the winner and increases the chance of future losses for the loser. Thus, the possible current losses due to war are weighed against the possible future benefits of weakening or eliminating one's opponent. In our model, the benefits to the winner come from the reduction or elimination of future arming but there are of course many other benefits that exist and that we briefly discuss.

The explanation for war that we advance is not meant to apply to the postWWII period only. Organized warfare has been central to the experience of humanity since the agricultural revolution. And, in particular, the place in which modern governance evolved - Western Europe - has had more than its share of civil and inter-state warfare. For example, most late Medieval Italian cities were wracked by clan warfare for centuries before they developed ways of limiting their arming through checks and balances, representative politics, or through autocracy. But what followed was warfare at a higher level in the whole Italian peninsula, between city-states, ecclesiastical states, and absolutist monarchs (that was the world that Machiavelli lived in; see McNeill (1982, Ch.3) or Tilly (1992, Chs 2 and 3) for overviews). It was only in the second half of the nineteenth century that Italy was unified. It would be hard to argue that all this warfare has been caused by asymmetric information, or to some systematic misperceptions and miscalculations. The combination of incomplete contracting and the fundamental non-stationarity or time-dependence of the future should be seriously considered as an explanation of open warfare that is complementary to existing ones. 


\section{The Basic Setting: War versus Armed Peace}

Consider two groups, $A$ and $B$, that compete for power and interact over an indefinite horizon. They compete for output of value $Y$. Because the two groups cannot write contracts on the ultimate source of enforcement, arms, they have to expend resources $r_{A}$ and $r_{B}$ to maintain their position. These expenditures are necessary regardless of whether War or "Armed Peace" ultimately prevails. ${ }^{4}$ In the event of War, arms affect the probabilities of winning for each side; we denote these probabilities by $p_{A}$ and $p_{B}$. (How these probabilities depend on arms is examined in the next section.) In the case of Peace, $r_{A}$ and $r_{B}$-through their effect on the probabilities of winning in the event of War - influence each group's bargaining position in arriving at a particular settlement.

If War were to take place only a fraction $\phi \in(0,1)$ of $Y$ can be consumed with the rest, $(1-\phi) Y$, being destroyed by the conflict. In each period, then, the expected single-period payoff of group $i=A, B$ in the event of War is:

$$
U_{i}^{w}=p_{i} \phi Y-r_{i}
$$

Given that war is destructive, in each period both sides would prefer to divide $Y$ in shares that equal their winning probabilities since it would result in a payoff of $p_{i} Y-r_{i}>p_{i} \phi Y-r_{i}=U_{i}^{w}$. A range of other possible divisions of $Y$ would also be Pareto superior to the payoffs under War. Under an indefinite repetition of such single-period simple interactions, there would never be an incentive to go to War, provided the two groups could costlessly communicate and output $Y$ is divisible.

However, if War were to occur, we would reasonably expect interactions between the two groups to be different in the future, perhaps fundamentally so. Given that the winner of the war would receive $\phi Y$ and the loser nothing, the

\footnotetext{
${ }^{4}$ The term "armed peace" is due to Jack Hirshleifer.
} 
resources that the winning side could command in the future can be expected to be higher than those of the winner which in turn could bias future wars even further in favor of today's winner. The winner could also gain possession of the state, something which could provide them both with greater resources that would not be obtainable otherwise and with greater ability to withstand challenges from the other group in the future. Such induced asymmetries could well make war an attractive possibility by trading off a lower expected payoff for today for more of it in the future.

For now we allow a stark and simple form of dependence of future power on today's war. We suppose that the loser of a war in any period would be unable to raise the resources that are necessary to challenge the winner in future periods and, thus, the winner would be able to enjoy the output $Y$ in all future periods whereas the loser receives nothing. (In Section 4 we illustrate how our findings extend to the less stark setting in which for a group to drop completely out of contention there is a series of battles, and not just one, that it would have to lose.)

Consider, then, the negotiations that would result in either Peace or War in any particular period in which no War has occurred in the past and each group has already invested its resources in guns (i.e., $r_{i}$ is a sunk investment). Further, and without loss of generality, suppose group $A$ is the one that has the initiative in making a proposal (by for example holding the reins of a perhaps weak government). In case of Peace, the group would receive the whole value of $Y$ and would make an offer of subsidy $S$ to group $B$, which would either accept or reject $A$ 's offer. If the offer were to be rejected, War would ensue. The resources that either party has invested in arms is considered sunk so that they play no more in current negotiations.

Assuming a discount factor $\delta \in(0,1)$, the discounted expected payoff for group $i$ in the event of War is the following: 


$$
V_{i}^{W}=p_{i} \phi Y+p_{i} \Sigma_{t=1}^{\infty} \delta^{t} Y+\left(1-p_{i}\right) \Sigma_{t=1}^{\infty} \delta^{t} 0=p_{i}\left(\phi+\frac{\delta}{1-\delta}\right) Y
$$

Note how in the event of War, since one group would be eliminated from contention, in the future no resources would be devoted to arming. Group $B$ would accept any offer $S$ from group $A$ that satisfies the following inequality:

$$
S+\delta V_{B}(S) \geq V_{B}^{W}
$$

where $V_{B}(S)$ denotes the continuation payoff of group $B$ when it is out of power given the subsidy $S$. As part of any Markov Perfect Equilibrium in which a positive subsidy is given, group $A$ would offer a subsidy $S^{*}$ that satisfies (3) as an equality. Assuming that $S^{*}$ would be accepted in this period, it would be acceptable in all future periods and therefore $V_{B}\left(S^{*}\right)=\frac{S^{*}-r_{B}}{1-\delta}$. Then, from (3) and (2), the subsidy would be:

$$
S^{*}=p_{B}[\phi(1-\delta)+\delta] Y+\delta r_{B}
$$

Note that this subsidy that must be offered by group $A$ to group $B$ in order to prevent War depends positively on the power of group $B$ (as proxied by its probability of winning $p_{B}$ ), on the share of output that is not destroyed in the event of War, on the discount factor, as well as on the value of output $Y$. However, this minimally acceptable subsidy to group $B$ might not be in group $A$ 's interest to offer. In particular, the resultant payoff of group $A$ should be preferable to its expected payoff under War, or

$$
Y-S^{*}+\delta V_{A}\left(S^{*}\right) \geq V_{A}^{W}
$$

where $V_{A}\left(S^{*}\right)=\frac{Y-S^{*}-r_{A}}{1-\delta}$ is the continuation payoff of group $A$ if peace were to prevail forever. Supposing the probabilities of winning for the two sides sum 
to one (i.e. $p_{A}+p_{B}=1$ ), it is straightforward to show that the condition for Armed Peace (so that (3) and (5) are both satisfied) is as follows:

$$
Y \geq \frac{\delta\left(r_{A}+r_{B}\right)}{(1-\phi)(1-\delta)}
$$

When this inequality is reversed, there would not be a subsidy that is feasible, and War would ensue. Thus, based on (6), War is more likely and Armed Peace is less likely,

(i) the lower is the contested output $Y$;

(ii) the higher are the resources devoted to arming $\left(r_{A}+r_{B}\right)$ by the two groups;

(iii) the higher is the discount factor $\delta$; and

(iv) the less destructive War is (or, the higher is $\phi$ ).

When contested output is low, as it presumably is in low-income countries, the current cost of going to War (controlling for $\phi$ ) is low (as that cost equals $Y(1-\phi))$, and therefore going to War becomes easier.

On the one hand, greater arming increases the likelihood of War because War tilts the balance of power in favor of one side and reduces (and in our case, completely eliminates) the future costs of arming; Armed Peace, on the other hand, as its name suggests necessitates incurring the cost of arming forever.

Given the long conditioning of folk-theorem arguments, the effect of the discount factor on War appears to be counterintuitive. Note that folk-theorem arguments merely describe the possibility of cooperation by means of supergame strategies, typically in stationary settings. Nothing guarantees cooperation in such settings because the accompanying strategies and equilibria are rather fragile and non-renegotiation proof. By contrast, we concentrate on regular strategies and equilibrium in a time-dependent setting. The more the future is valued, as indicated by a higher value of the discount factor $\delta$, the greater the 
salience of the expected future rewards is compared to the current costs of War and therefore the higher is the likelihood of War.

Thus far the resources devoted to arms $\left(r_{A}\right.$ and $\left.r_{B}\right)$ have been considered exogenous parameters. That might well be the case in many low-income countries if the groups involved face liquidity constraints and organizational disadvantages that prevent them from increasing their arming to levels that would be consistent with an unconstrained equilibrium. Arms embargoes and difficulties in accessing the international arms market could also play a role in restraining arming to levels that can be considered as given. We next consider conditions in which no such constraints exist.

\section{Endogenous Arming}

To allow for endogenous arming, we first need to specify how probabilities of winning depend on arming. We suppose that these probabilities depend on arming through the following additive contest success function (see Tullock, 1980, and Hirshleifer, 1989):

$$
p_{i}\left(r_{A}, r_{B}\right)=\frac{r_{i}^{m}}{r_{A}^{m}+r_{B}^{m}} \text { where } i=A, B \text { and } m \in(0,1]
$$

The parameter $m$ has been described as a measure of the effectiveness of decisiveness of conflict. A higher value of this parameter could be associated with more advanced forms of warfare that might have been traditionally less prevalent in many low-income countries but is now available there.

Further, suppose that arming is available at constant marginal cost $\omega>0$. Given that an integral part of the cost of arming is actually the cost of hiring soldiers and since the cost of labor is lower in low-income countries, we expect a lower $\omega$ to be associated with lower incomes.

Note that when group $A$ contemplates whether to offer a subsidy to group $B$ 
or go to War, the continuation payoff of group $B$ would still be the one described in (2). Conditional on Armed Peace, the subsidy that would just induce $B$ not to go to War is the following variation of (4):

$$
S^{*}\left(r_{A}^{P}, r_{B}^{P}\right)=p_{B}\left(r_{A}^{P}, r_{B}^{P}\right)[\phi(1-\delta)+\delta] Y+\delta \omega r_{B}^{P}
$$

where $r_{A}^{P}$ and $r_{B}^{P}$ denote arming under Armed Peace, which in general can be different than arming under War. The payoff functions of the two groups under Armed Peace would then be as follows:

$$
\begin{aligned}
V_{A}^{P}\left(r_{A}^{P}, r_{B}^{P}\right) & =\frac{1}{1-\delta}\left\{Y-p_{B}(\phi(1-\delta)+\delta) Y-\delta \omega r_{B}^{P}-\omega r_{A}^{P}\right\} \\
V_{B}^{P}\left(r_{A}^{P}, r_{B}^{P}\right) & =\frac{1}{1-\delta}\left\{p_{B}(\phi(1-\delta)+\delta) Y-\delta \omega r_{B}^{P}-\omega r_{B}^{P}\right\}
\end{aligned}
$$

If there were to be Armed Peace, equilibrium arming would be:

$$
r_{A}^{P *}=r_{B}^{P *}=r^{P *}=\frac{m}{2 \omega}(\phi+\delta(1-\phi)) Y
$$

The effects of different variables on equilibrium arming under Armed Peace are intuitively plausible, but it is worth noting how the negative effect on arming of lower output (and income) $Y$ is counteracted by the positive effect of a lower wage income $\omega$.

For Armed Peace to be an equilibrium, however, both inequalities (3) and (5) would still need to be satisfied. Substituting the equilibrium arms in (11) in (9) and (10), and comparing these to the continuation payoffs under War we can show that Armed Peace can prevail if and only if the following condition is satisfied:

$$
\frac{2 \omega}{2 \omega+m} \geq \phi+\delta(1-\phi)
$$


Before discussing this condition, we analyze the equilibrium if War were to occur. The payoffs under War are the following:

$$
V_{i}^{W}\left(r_{A}^{W}, r_{B}^{W}\right)=p_{i}\left(r_{A}^{W}, r_{B}^{W}\right)\left(\frac{\phi+\delta(1-\phi)}{1-\delta}\right) Y-\omega r_{i}^{W}
$$

It is straightforward to show that equilibrium arming has a noteworthy property:

$$
r_{A}^{W *}=r_{B}^{W *}=\frac{m}{2 \omega(1-\delta)}[\phi+\delta(1-\phi)] Y=\frac{r^{P *}}{1-\delta}
$$

That is, arming under War is much more intense than if Armed Peace were to prevail and it exactly equals the discounted sum of all future arming if Armed Peace were to prevail. That appears plausible, as War involved fighting for all future streams of output whereas Armed Peace involves the division of current output only. Because War involves such high expenditures on arming we might expect the adversaries to face serious liquidity constraints so that War might be averted in some cases. However, as Collier et. al. (2003, p. 77) have found, recently rebel groups raise funds by selling the advance rights to the extraction of minerals that they currently do not control, and thus are able to at least partly circumvent the severe liquidity constraints that War entails.

Going back to the condition (12) for War and Peace, we can conclude that War is more likely and Armed Peace less likely when

(i) wage income and the cost of arming as indicated by $\omega$ are low;

(ii) the effectiveness of conflict as represented by $m$ is high;

(iii) the higher is the discount factor $\delta$; and

(iv) the less destructive War is (or, the higher is $\phi$ ).

Items (iii) and (iv) are identical to those in the previous section where arming is exogenous. By endogenizing arming, not only have we eliminated arms from the condition, we have also eliminated contested output $Y$ as well. Instead, 
we have two additional features that increase the likelihood of War: the higher effectiveness of modern conflict that can be more easily imported nowadays and the lower cost of arming that comes from lower wages.

\section{Multiple Victories for Winning the War}

Our analysis thus far assumes that one War determines the victor, yet completely eliminating one's opponent is often only achieved after a series of smaller victories. We here extend the basic model from Section 2 into a repeated game in which more than one War, more appropriately called a battle in this context, must be won in order to achieve total victory.

In any given period $t, \mathrm{~A}$ and $\mathrm{B}$ will again make the same War-or-Armed Peace decision as before, yet now their interaction will depend on the existing state of relative power which can differ over time. To keep the analysis as simple as possible, we will suppose there are five states, $x=0,1, \ldots, 4$. Moreover, let $x$ denote the relative strength of $\mathrm{A}$ and $\mathrm{B}$, so that if they are in state $x$ at time $t$, then A wins the next armed conflict with probability $p_{A}=\frac{x}{4}$. Should conflict occur in this state and A wins, then the setting moves to state $x+1$ in time $t+1$, while if $\mathrm{B}$ wins, then the setting moves to state $x-1$ in time $t+1$. A achieves

total victory by winning enough battles to reach state 4 , since $p_{A}=\frac{4}{4}=1$ in that state. Conversely, B achieves total victory by reaching state 0 .

Further suppose that the last winner of an open conflict has temporary control over the resources not destroyed by the fighting, and is the player in position to make a settlement offer. Specifically, let A be the proposer in state 3 , let B be the proposer in state 1, and let either A or B be the proposer in state 2 depending on who won the prior War. The idea here is that if we start in the even strength state 2 , then states 1 and 3 are only ever reached by a victory by $\mathrm{B}$ or $\mathrm{A}$, respectively, in the prior period. 
Notice how winning a War brings the victor closer to Total Victory in two ways. First, winning today brings the state closer to the Total Victory state, and second, winning today increases the chances of winning the future Wars that are needed to achieve that Total Victory. Also note that the basic setting presented earlier in Section 2 would be a three state, $x=0,1$, 2 , version of this model in which $p_{A}=\frac{x}{2}$.

This type of competition has been termed a "tug-of-war" by earlier researchers because of the potential for each side to move from a position of strength to weakness, and because the contest occurs over many periods. For example, Harris and Vickers (1987) use a multi-state race with contest success functions to study an $R \& D$ race in which each organization achieves victory only after separating itself from its rival, and Budd, Harris, and Vickers (1993) examine duopoly firms in a similar race achieve market dominance. That said, the nature of the tug-of-war in our model differs in one key respect. In addition to one side's victory today bringing them closer to total victory, victory today also confers an additional advantage by increasing the victor's relative strength today. That is, the victory today increases the likelihood that the same group will be the victor again the next period. This changing of relative power acts to increase the benefits of victory today while also increasing the cost of losing today. Our work also differs in that we apply the tug-of-war model to a new setting of War and Armed Peace.

To examine which is optimal, War versus Armed Peace, for each group requires multiple steps in the logic. First, we must find the value functions for the situation in which War always occurs in each of the contention states $x=1,2,3$. Next, we calculate what settlements must be offered to avert War and sustain Armed Peace in each period. This procedure, which is detailed in the appendix, yields the following four conditions for a Markov Perfect Equilibrium: ${ }^{5}$

\footnotetext{
${ }^{5}$ See Fudenberg and Tirole (1996) for a discussion of the Markov Perfect Equilibrium
} 
- In state 3, A will offer an accepted subsidy only if

$$
Y \geq 3 \delta \frac{\left(\delta^{2}+8 \delta-\delta^{3}\right) r_{A}+\left(8-\delta^{2}+\delta^{3}\right) r_{B}}{8\left(4-3 \delta-\delta^{2}\right)(1-\phi)} .
$$

- In state 2 , if $\mathrm{A}$ is the proposer, an accepted subsidy will be made only if

$$
Y \geq 3 \delta^{2} \frac{2(1+\delta) r_{A}+(1+\delta) r_{B}}{3+(13-12 \phi)\left(1-\delta^{2}\right)} .
$$

- In state 2 , if $\mathrm{B}$ is the proposer, an accepted subsidy will be made only if

$$
Y \geq 3 \delta^{2} \frac{2(1+\delta) r_{B}+(1+\delta) r_{A}}{3+(13-12 \phi)\left(1-\delta^{2}\right)}
$$

- In state $1, \mathrm{~B}$ will offer an accepted subsidy only if

$$
Y \geq 3 \delta \frac{\left(\delta^{2}+8 \delta-\delta^{3}\right) r_{B}+\left(8-\delta^{2}+\delta^{3}\right) r_{A}}{8\left(4-3 \delta-\delta^{2}\right)(1-\phi)} .
$$

Equations (15)-(18) are directly related to condition (6) for Armed Peace in the basic setting examined in Section 2. Again, War is more likely in any period and any state when:

(i) the lower is the contested output $Y$;

(ii) the higher are the resources devoted to arming $\left(r_{A}+r_{B}\right)$ by the two groups;

(iii) the higher is the discount factor $\delta$; and

(iv) the less destructive War is (or, the higher is $\phi$ ).

Notice that the conditions for War in multi-stage conflict are qualitatively identical to those found using the basic model in Section 2. Thus, the basic model captures the primary strategic elements at work in the choice between War and Armed Peace.

However, the conditions are not identical quantitatively, and we can ask whether Armed Peace is more likely when total victory requires more War victories. To find out, we check whether equation (6) is less likely to be met concept. 
than equations (15)-(18). To simplify this comparison, further suppose that $r_{A}=r_{B}=r$. The symmetry implied by this assumption means that we need only compare (6) with (15) and (16), since (17) and (18) will now be identical to (15) and (16), respectively.

With this additional symmetry, (6) becomes

$$
Y \geq \frac{2 \delta r}{(1-\phi)(1-\delta)},
$$

and (15) and (16), respectively, become

$$
Y \geq \frac{3 \delta(\delta+1) r}{\left(4-3 \delta-\delta^{2}\right)(1-\phi)}
$$

and

$$
Y \geq \frac{9 \delta^{2}(1+\delta) r}{3+(13-12 \phi)\left(1-\delta^{2}\right)} .
$$

A little bit more algebra reveals that (20) and (21) are both less than (19) (since $\delta$ and $\phi$ are both less than 1) . Thus, requiring more victories does increase the likelihood of Armed Peace. Requiring more victories lengthens the time it may take to achieve total victory, thereby increasing the cost of defeating one's opponent.

Although Armed Peace is more likely in this setting, it is not guaranteed. In technical terms, Armed Peace never becomes the only equilibrium for all parameter settings. This is true even if the model were extended to a larger number of states, whereby a larger number of Wars must be won for total victory to be achieved. The reason is that there is always an incentive to achieve total victory since it is the only way to avoid costly arming. As long as this total victory incentive exists, there is an incentive to fight, and the question is whether or not the benefits to Armed Peace outweigh those of fighting. As our analysis shows, many conditions present in low income countries are those that make Armed Peace less likely even if total victory requires winning a series of battles. 


\section{Concluding Remarks}

Why does conflict occur, and disproportionately so in low-income countries? Our analysis examines two key factors, that adversaries cannot make long-term contracts to enforce disarmament, and that open conflict changes the strategic nature of future interaction. Our analysis also considers two key features of lowincome countries, that adversaries can make short-run (as distinguished from long-term) contracts, and that achieving total victory prevents one from having to spend resources towards arming. Even though total victory, once achieved, is in some sense efficient because it no longer requires costly arms buildup, the only way to achieve it is through open conflict, which is inefficient because, not only does it require the costly buildup of arms, but it also leads to the destruction of resources. Armed Peace is thus a possible middle ground.

However, our analysis shows that Armed Peace is not inevitable because the incentives to fight are strong. Our basic model shows that conflict is more likely than Armed Peace in low-income countries with low contested output, large resources devoted to arming, high discount factors, and less destructive war. When opponents choose their arming levels, we find that conflict is more likely with low wages and low arming costs. Prolonging the length of time necessary to achieve total victory may increase the chances of Armed Peace, although the same conditions as those above will still lead to conflict. The lure of total victory and its impact on future strategic positioning remains a strong incentive to engage in open conflict.

In short, the combination of incomplete contracting and the possibility of total victory leads to conflict. If parties can make long-term contracts, then the destructive nature of War leads to settlement that makes each side better off than fighting. Moreover, even if parties are unable to make long-term contracts, there still might exist the possibility of short-term contracts that can 
be enforced by each side's threat to fight. However, even these short-term contracts might not be enough to enable Armed Peace. If conflict today alters the future positions of the adversaries, then one or more parties might forgo the short-term relative safety of Armed Peace and opt for the chance of total victory and its associated high benefits by open conflict.

We conclude that the shadow of the future looms large in low-income countries that exhibit the many factors conducive to War described herein. Achieving a lasting peace will require the development of institutions necessary to enforce it, that is, the institutions necessary to foster peaceful resolutions to competition over scarce resource. Since these institutions are costly to implement (Gradstein, 2004) and take time to develop (Genicot and Skaperdas, 2002), ${ }^{6}$ our findings suggest that low-income countries can remain in a vicious cycle of poverty and violent civil or political violence for prolonged periods.

\section{Appendix}

Let $V_{i}^{t}(x)$ denote $i$ 's present discounted value of being in state $x$. The value functions for the total victory states are thus $V_{A}^{t}(0)=0, V_{A}^{t}(4)=\frac{Y}{1-\delta}, V_{B}^{t}(0)=$ $\frac{Y}{1-\delta}$, and $V_{B}^{t}(4)=0$. Note that in the total victory states there is no need to arm by expending $r_{A}$ or $r_{B}$ since the opponent has been eliminated.

To examine which is optimal for the groups, War versus Armed Peace, in the other states requires two steps in the logic. We first find the value functions for the situation in which War always occurs in each of the contention states $x=1,2,3$. Next, we calculate what settlements must be offered to avert War and sustain Armed Peace in each period. In this manner, we obtain the conditions for a Markov Perfect Equilibrium.

\footnotetext{
${ }^{6}$ Of course, external shocks may help a country get started on a good path. McBride (forthcoming), for example, shows how economic crises in low income countries may actually lead to economic reforms and a decline in conflict.
} 
Value functions under War in each period. War in a contested state yields the following value functions

$$
\begin{aligned}
V_{A}^{W, t}(1) & =\frac{1}{4}\left(\phi Y+\delta V_{A}^{t+1}(2)-\delta r_{A}\right) \\
V_{A}^{W, t}(2) & =\frac{1}{2}\left(\phi Y+\delta V_{A}^{t+1}(3)-\delta r_{A}\right)+\frac{1}{2}\left(\delta V_{A}^{t+1}(1)-\delta r_{A}\right) \\
V_{A}^{W, t}(3) & =\frac{3}{4}\left(\phi Y+\delta \frac{Y}{1-\delta}-\delta r_{A}\right)+\frac{1}{4}\left(\delta V_{A}^{t+1}(2)-\delta r_{A}\right) \\
V_{B}^{W, t}(1) & =\frac{3}{4}\left(\phi Y+\delta \frac{Y}{1-\delta}-\delta r_{B}\right)+\frac{1}{4}\left(\delta V_{B}^{t+1}(2)-\delta r_{B}\right) \\
V_{B}^{W, t}(2) & =\frac{1}{2}\left(\phi Y+\delta V_{B}^{t+1}(1)-\delta r_{B}\right)+\frac{1}{2}\left(\delta V_{B}^{t+1}(3)-\delta r_{B}\right) \\
V_{B}^{W, t}(3) & =\frac{1}{4}\left(\phi Y+\delta V_{B}^{t+1}(2)-\delta r_{B}\right) .
\end{aligned}
$$

To find the present discounted values for group A if War occurs in every contested period, plug (22) and (24) into (23) to solve for $V_{A}^{W}(2)$, and then plug that back into (22) and (24). Do a similar procedure for group B. The results are:

$$
\begin{aligned}
V_{A}^{W}(1)= & \frac{\left(8 \phi-2 \delta^{2} \phi-4 \delta \phi-2 \delta^{3} \phi+3 \delta^{3}\right) Y+\left(3 \delta^{4}+5 \delta^{3}-8 \delta\right) r_{A}}{8(1-\delta)\left(4-\delta^{2}\right)} \\
V_{A}^{W}(2)= & \frac{\left(3 \delta^{2}-4 \delta^{2} \phi+4 \phi\right) Y+\left(5 \delta^{3}+3 \delta^{2}-8 \delta\right) r_{A}}{2(1-\delta)\left(4-\delta^{2}\right)} \\
V_{A}^{W}(3)= & \frac{\left(24 \phi-20 \delta \phi-6 \delta^{2} \phi+2 \delta^{3} \phi+24 \delta-3 \delta^{3}\right) Y}{8(1-\delta)\left(4-\delta^{2}\right)} \\
& +\frac{\left(11 \delta^{3}-3 \delta^{4}-32 \delta+24 \delta^{2}\right) r_{A}}{8(1-\delta)\left(4-\delta^{2}\right)} \\
V_{B}^{W}(1)= & \frac{\left(24 \phi-20 \delta \phi-6 \delta^{2} \phi+2 \delta^{3} \phi+24 \delta-3 \delta^{3}\right) Y}{8(1-\delta)\left(4-\delta^{2}\right)} \\
& +\frac{\left(11 \delta^{3}-3 \delta^{4}-32 \delta+24 \delta^{2}\right) r_{B}}{8(1-\delta)\left(4-\delta^{2}\right)} \\
& \frac{\left(3 \delta^{2}-4 \delta^{2} \phi+4 \phi\right) Y+\left(5 \delta^{3}+3 \delta^{2}-8 \delta\right) r_{B}}{2(1-\delta)\left(4-\delta^{2}\right)} \\
V_{B}^{W}(2)= & \frac{\left(8 \phi-2 \delta^{2} \phi-4 \delta \phi-2 \delta^{3} \phi+3 \delta^{3}\right) Y+\left(3 \delta^{4}+5 \delta^{3}-8 \delta\right) r_{B}}{8(1-\delta)\left(4-\delta^{2}\right)} .(33) \\
V_{B}^{W}(3)= &
\end{aligned}
$$

We will use these equations in a moment when we determine when Armed 
Peace or open conflict will result from optimizing behavior.

When Armed Peace is optimal. Let $S_{i}(x)$ be the offer made by $i$ in state $x$. Note that if $i$ 's offer is accepted by $j$ in state $x$ in period $t$, then that same offer would be accepted in period $t+1$ because they would still be in state $x$. Thus, to determine what $S_{i}(x)$ would be accepted by $j$, we compare the infinite stream of $S_{i}(x)$ 's that $j$ would get with what $j$ would get going to War from period $t$ on. For state 3 , this comparison is

$S_{A}(3)+\frac{\delta}{1-\delta}\left(S_{A}(3)-r_{B}\right) \geq \frac{\left(8 \phi-2 \delta^{2} \phi-4 \delta \phi-2 \delta^{3} \phi+3 \delta^{3}\right) Y+\left(3 \delta^{4}+5 \delta^{3}-8 \delta\right) r_{B}}{8(1-\delta)\left(4-\delta^{2}\right)}$,

where the RHS is equation (26). Since A will make the smallest such offer that satisfies the inequality, setting this to equal yields

$$
S_{A}^{*}(3)=\frac{\left(8 \phi-2 \delta^{2} \phi-4 \delta \phi-2 \delta^{3} \phi+3 \delta^{3}\right) Y+\left(24 \delta-3 \delta^{3}+3 \delta^{4}\right) r_{B}}{8\left(4-\delta^{2}\right)} .
$$

Doing similar calculations for the other states yields

$$
\begin{aligned}
& S_{A}^{*}(2)=\frac{1}{2} \frac{\left(3 \delta^{2}-4 \delta^{2} \phi+4 \phi\right) Y+\left(3 \delta^{3}+3 \delta^{2}\right) r_{B}}{2\left(4-\delta^{2}\right)} \\
& S_{B}^{*}(2)=\frac{1}{2} \frac{\left(3 \delta^{2}-4 \delta^{2} \phi+4 \phi\right) Y+\left(3 \delta^{3}+3 \delta^{2}\right) r_{A}}{2\left(4-\delta^{2}\right)} \\
& S_{B}^{*}(3)=\frac{\left(8 \phi-2 \delta^{2} \phi-4 \delta \phi-2 \delta^{3} \phi+3 \delta^{3}\right) Y+\left(24 \delta-3 \delta^{3}+3 \delta^{4}\right) r_{A}}{8\left(4-\delta^{2}\right)} .
\end{aligned}
$$

We must now ask when making one of these offers is optimal for the proposer. A will offer $S_{A}^{*}(3)$ in state 3 if doing so now and forever is better than fighting forever:

$$
\begin{aligned}
& Y-S_{A}^{*}(3)+\frac{\delta}{1-\delta}\left(Y-S_{A}^{*}(3)-r_{A}\right) \\
\geq & \frac{\left(24 \phi-20 \delta \phi-6 \delta^{2} \phi+2 \delta^{3} \phi+24 \delta-3 \delta^{3}\right) Y}{8(1-\delta)\left(4-\delta^{2}\right)}+\frac{\left(11 \delta^{3}-3 \delta^{4}-32 \delta+24 \delta^{2}\right) r_{A}}{8(1-\delta)\left(4-\delta^{2}\right)},
\end{aligned}
$$

where the RHS is from equation (33). Some algebra reduces this condition to

$$
Y \geq 3 \delta \frac{\left(\delta^{2}+8 \delta-\delta^{3}\right) r_{A}+\left(8-\delta^{2}+\delta^{3}\right) r_{B}}{8\left(4-3 \delta-\delta^{2}\right)(1-\phi)},
$$


which is exactly equation (15).

Doing the same comparison for an offer by A in state 2 yields condition

$$
Y \geq 3 \delta^{2} \frac{2(1+\delta) r_{A}+(1+\delta) r_{B}}{3+(13-12 \phi)\left(1-\delta^{2}\right)},
$$

which is equation (16).

Finally, repeating the process for B in states 2 and 1 yields

$$
\begin{aligned}
& Y \geq 3 \delta^{2} \frac{2(1+\delta) r_{B}+(1+\delta) r_{A}}{3+(13-12 \phi)\left(1-\delta^{2}\right)} \\
& Y \geq 3 \delta \frac{\left(\delta^{2}+8 \delta-\delta^{3}\right) r_{B}+\left(8-\delta^{2}+\delta^{3}\right) r_{A}}{8\left(4-3 \delta-\delta^{2}\right)(1-\phi)}
\end{aligned}
$$

respectively, which are equations (17) and (18).

\section{$7 \quad$ References}

Acemoglu, Daron, and James Robinson, 2000, "Why did the West Extend the Franchise? Democracy, Inequality, and Growth in Historical Perspective," Quarterly Journal of Economics, 115, 1167-1199.

Bester, Helmut and Kai Konrad, 2004, "Delay in Contests," European Economic Review 48 (5), 1169-1178.

Bester, Helmut and Kai Konrad, 2005, "Easy targets and the timing of conflict," Journal of Theoretical Politics, 17 (2): 199-215.

Bester, Helmut and Karl Warneryd, 1998, "Conflict Resolution Under Asymmetric Information."

Brito, Dagobert and Michael Intriligator, 1985, "Conflict, War and Redistribution," American Political Science Review, 79 (4), 943-957.

Budd, Christopher, Christopher Harris, and John Vickers, 1993, "A Model of the Evolution of Duopoly: Does the Asymmetry between Firms Tend to Increase or Decrease?" Review of Economic Studies, 60, 543-573. 
Collier, Paul, Elliott V.L., Hegre Havard, Hoeffler, Anke, ReynalQuerol, Marta, and Sambanis, Nicholas, Breaking the Conflict Trap; Civil War and Development Policy, (World Bank Policy Report), 2003, Washington, DC: World Bank and Oxford University Press.

Fearon, James, 1995, "Rationalist Explanations for War," International Organization, 49(3), 379-414.

Fearon, James, and David D. Laitin, 2003, "Ethnicity, Insurgency, and Civil War." American Political Science Review 97(1), 75-90.

Fudenberg, Drew, and Jean Tirole, 1996, Game Theory, Cambridge: MIT Press.

Garfinkel, Michelle and Stergios Skaperdas, 2000, "Conflict Without Misperception or Incomplete Information: How the Future Matters," Journal of Conflict Resolution, 44(6), 793-807.

Genicot, Garance and Stergios Skaperdas, 2002, "Investing in Conflict Management," Journal of Conflict Resolution, 46, 154-170.

Gradstein, Mark, 2004, "Governance and Growth," Journal of Development Economics, 73, 505-518.

Grossman, Sanford and Oliver Hart, 1986, "The Costs and Benefits of Ownership: A Theory of Vertical and Lateral Integration," Journal of Political Economy, 84, 691-719.

Harris, Christopher and John Vickers, 1987, "Racing with Uncertainty," Review of Economics Studies, 54, 1-21.

Hess, Gregory, 2003, "The Economic Welfare Cost of Conflict: An Empirical Assessment," CESifo Working paper, No. 852. 
Hirshleifer, Jack, 1989, "Conflict and Rent-seeking Success Functions: Ratio Vs. Difference Models Of Relative Success." Public Choice, 63(2), 101-12.

McBride, Michael, 2004, "Clientelism, Coups, and Commitment."

McBride, Michael, forthcoming, "Crises, Reforms, and Regime Persistence in sub-Saharan Africa," European Journal of Political Economy.

McNeill, William, 1982, The Pursuit of Power, Chicago: University of Chicago Press.

Mehlum, Halvor and Karl Moene, forthcoming, "Fighting Against the Odds," Economics of Governance.

Powell, Robert, forthcoming, "War as a Commitment Problem," International Organization.

Sambanis, Nicholas, 2004, "Using Case Studies to Expand Economic Models of Civil War," Perspectives on Politics, 2(2), 259-279.

Skaperdas, Stergios, 2003, "An Economic Approach to Analyzing Civil Wars," UC Irvine Working Paper 02-03-18.

Skaperdas, Stergios and Constantinos Syropoulos, 1996, "Can the Shadow of the Future Harm Cooperation," Journal of Economic Behavior and Organization, 29, 355- 372 .

Tilly, Charles, 1992, Coercion, Capital and European States, New York: Blackwell

Tullock, Gordon, 1980, "Efficient Rent Seeking." In Toward a Theory of the Rent Seeking Society, edited by James M. Buchanan, Robert D. Tollison, and Gordon Tullock, College Station: Texas A\&M University Press, 3-15. 